\title{
$\mathrm{PRB}$ 지진격리장치의 성능 검증을 위한 해석 및 실험적 연구
}

\author{
김 성 조'김 세 윤 ${ }^{1} \cdot$ 지 용 수 $^{3}$ 김 봉 식 ${ }^{4}$ 한 동 석 $^{2 \dagger}$ \\ ${ }^{1}$ 연세대학교 건설환경공학과 대학원생, ${ }^{2}$ 연세대학교 건설환경공학과 교수, ${ }^{3}$ (주)펜타드 대표이사, ${ }^{4}($ 주 $)$ 펜타드 연구소장
}

\section{Study on the Performance Verification of PRB Isolation Device using Simulation and Experiment}

\author{
Sung-Jo Kim ${ }^{1}$, Se-Yun Kim ${ }^{1}$, Yongsoo $\mathrm{Ji}^{3}$, Bongsik Kim ${ }^{4}$ and Tong-Seok $\mathrm{Han}^{2}{ }^{\dagger}$ \\ ${ }^{1}$ Graduate Student, Department of Civil and Environmental Engineering, Yonsei University, Seoul, 03722, Korea \\ ${ }^{2}$ Professor, Department of Civil and Environmental Engineering, Yonsei University, Seoul, 03722, Korea \\ ${ }^{3}$ Representative Director, Pentad Inc., Bucheon, 14424, Korea \\ ${ }^{4}$ Research Director, Pentad Inc., Bucheon, 14424, Korea
}

\begin{abstract}
This study introduces a technique for improving the elastomeric-isolator performance using modular devices. The modular devices are shear resistance block, polymer spring, displacement acceptance guide, and anti-falling block. They are installed on the elastomeric isolator as a supplementary device. Each modularized device improves the isolator performance by performing step-by-step actions according to the seismic intensity and displacement. The PRB isolation device works in four stages, depending on the seismic magnitude, to satisfy the target performance. It is designed to accommodate design displacement in the first stage and large magnitude of earthquakes in the second and third stages. This design prevents superstructures from falling in the fourth stage due to large-magnitude earthquakes by increasing the capacity limit of the elastomeric isolator. In this study, the PRB isolation device is analyzed using finite element analysis to verify that the PRB isolation device works as intended and it can withstand loads corresponding to large-magnitude earthquakes. The performance of the PRB isolation device is validated by the analysis, which is further corroborated by actual experiments.
\end{abstract}

Keywords : seismic isolation device, performance rubber bearing, polymer spring, finite element analysis

\section{1. 서 론}

1994년 미국 노스리지(Northridge)지진, 1995년 고베대지진 과 같은 큰 규모의 지진을 겪으면서 내진설계의 기본개념이 하중 기 반설계에서 성능기반 내진설계(Performance based seismic design) 로 전환되는 계기를 맞게 되었다(Priestley, 2000). 지진의 안전지 대로 인식된 우리나라에서도 최근 몇 년 사이 울산, 경주 그리고 포항에서 잇달아 지진이 발생했고, 1978년에서 1998년까지 지 진 발생 횟수가 평균 19.1회에서 1999년 이후엔 평균 69.9회로 약 3 배 이상 증가함에 따라 한반도는 지진에 대해서 안전지대라 는 인식에 변화가 생기게 되었으며, 국내에서도 구조물의 성능 기반 내진설계를 주제로 하는 다양한 연구가 활발히 수행되었다.

\footnotetext{
${ }^{\dagger}$ Corresponding author:

Tel: +82-2-2123-5801; E-mail: tshan@yonsei.ac.kr Received June 3 2020; Revised July 8 2020;

Accepted July 152020

C) 2020 by Computational Structural Engineering Institute of Korea
}

지진이 발생하면 지반의 운동으로 인해 지진 에너지가 생성 되고, 이는 구조물에 전달되어 손상, 파손, 이탈 등의 심각한 피 해를 주어 유지보수를 위한 막대한 비용을 발생시킨다. 현재 지진에 의한 구조물의 피해를 방지하기 위해 다양한 방법이 활 용되고 있으며(Keum et al., 1994; Kim et el., 2019), 그 중에서 지진격리장치를 사용한 내진설계는 상시에도 차량의 통행으 로 진동에 의한 영향을 받는 교량에 자주 활용된다. 교량은 온 도 편차에 따른 수축과 팽창, 바람(풍하중) 등의 다양한 환경 변화로 발생하는 상시 변위를 수용할 수 있어야 하며, 지진 시 구조물에 전달되는 지진동을 수용 및 소산하여 구조물에 피해 를 최소화하여야 할 필요가 있다. 교량의 지진격리장치로 다 양한 형태의 면진 받침이 사용되나 비용적인 측면을 고려했을

This is an Open-Access article distributed under the terms of the Creative Commons Attribution Non-Commercial License(http://creativecommons. org/licenses/by-nc/3.0) which permits unrestricted non-commercial use, distribution, and reproduction in any medium, provided the original work is properly cited. 


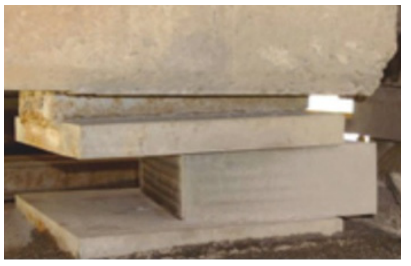

(a) Sliding

(c) Breakaway

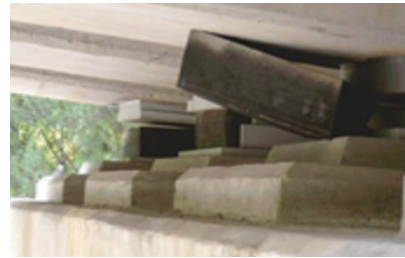

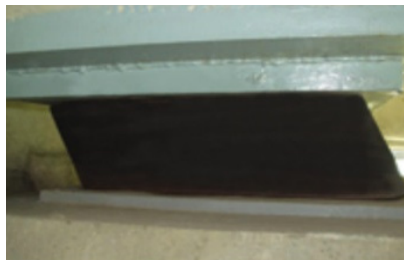

(b) Rollover

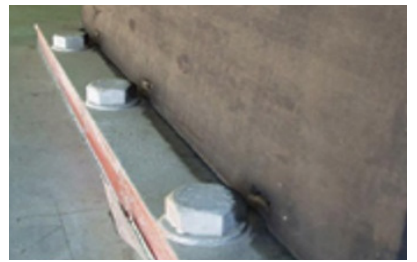

(d) Tear
Fig. 1 Problems of elastomeric isolator

때, 보편적으로 탄성받침이 가장 많이 활용된다. 탄성받침은 구조물의 상부구조와 하부구조를 이격시키고 탄성체가 하중 과 변위를 일정 구간 수용함으로써 구조물에 작용하는 하중 및 변위를 상쇄시킨다. 이러한 탄성받침은 KS규격으로 규정하고 있는 표준장치이지만, Fig. 1 에서 나타난 것처럼 탄성받침의 탄성패드에서 미끄럼, 롤오버(Rollover), 찢어짐, 이탈 등의 많 은 문제점을 나타내고 있고, 변위가 크게 발생하면 교량의 상 부구조가 낙교될 수 있어 큰 피해를 일으킬 수 있다. 그러므로 본 연구에서는 이러한 탄성받침의 단점을 극복하기 위해 규 모가 큰 지진에 대해 구조물의 안전성을 확보할 수 있는 PRB (Performance based Rubber Bearing) 지진격리장치를 유한요 소해석과 실험을 통해 성능을 검증하였다.

\section{PRB 지진격리장치 설계}

\subsection{PRB 지진격리장치 형상 및 제원}

$\mathrm{PRB}$ 지진격리장치는 기존에 상용화되어 있는 탄성받침에 모듈화된 장치들을 추가로 적용하여 기존의 상용화된 탄성받 침보다 추가적인 변위를 수용할 수 있도록 설계되었으며 각각 의 모듈이 단계별 변위에서 설계된 성능을 발휘할 수 있도록 고안된 지진격리장치이다. Fig. 2는 PRB 지진격리장치의 개요 도를 나타내었으며, 모듈화된 장치들의 형상은 Fig. 3에 나타 내었다. 지진격리장치의 상판에 구조물의 상부구조가 연결되 고, 하판은 앵커 소켓을 이용하여 하부구조와 연결된다. 지진 격리장치의 상판과 하판 사이에 탄성체와 모듈화된 장치들이 위치하여 상부구조와 하부구조를 이격시킨다. 상부구조와 하 부구조를 이격시킴으로써 지진 시 진동에 의한 구조물의 영향 을 감소시키고, 구조물에 전달되는 지진하중을 소산하므로 구 조물 피해를 감소시킬 수 있다. 모듈화된 장치는 변위수용 가이

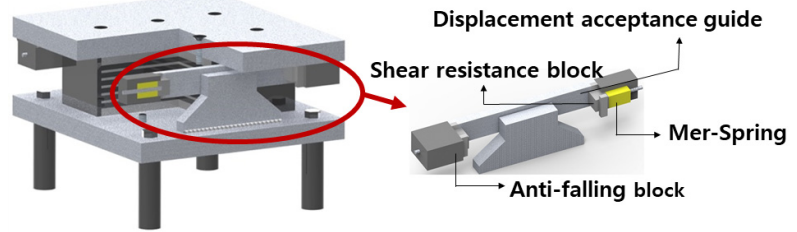

Fig. 2 Diagram of PRB isolation device

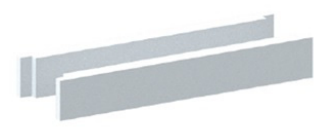

(a) Displacement acceptance guide

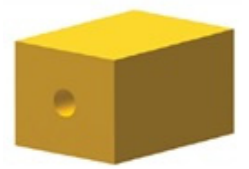

(c) MER-Spring

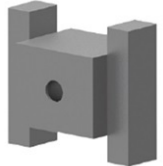

(b) Shear resistance block

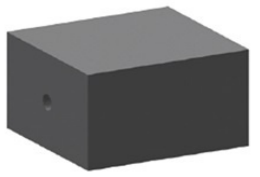

(d) Anti-Falling block
Fig. 3 Modularized devices

드, 초기전단저항 블럭, 완충장치(MER-Spring, Mass Energy Regulator Spring), 낙교방지블럭으로 구성되어 있으며, Fig. 2 와 같이 지진격리장치의 상판에 결합되고, 하판과 결합되는 쐐기와 맞물리게 설계되어 상부구조의 변위를 수용 및 제한할 수 있게 된다. 앵커소켓은 SS275, 초기전단저항 블럭은 SS275 이 상인 재질로 구성되며, 두 장치를 제외한 상판, 변위수용가이드, 초기전단저항 블럭 등은 SM355(Lee et al., 2017), 완충장치는 폴 리우레탄(Polyurethane)으로 설계되었으며, 모든 장치는 KS규격 을 만족한다. 각각의 장치는 용량에 무관하게 호환 가능하며, 모 듈화로 인해 점검, 수정, 교체 등이 간단하여 유지관리 비용을 줄일 수 있도록 설계되어 경제적인 운영관리가 가능하다.

\subsection{PRB 지진격리장치의 거동특성}

지진의 규모가 커질수록 탄성받침에 전달되는 변위 및 하중 이 증가하게 된다. 이를 소산하기 위해선 탄성받침 내부의 탄 성체의 크기가 커져야 하지만 탄성받침은 구조물의 하부구조 에 제한을 받아 크기에 한계가 있다. 이러한 기존 탄성받침의 문제점을 본 연구에서 제안하는 PRB 지진격리장치의 모듈화 된 장치들이 단계별 변위와 지진 강도에 따라 작동하도록 함으 로써 해결할 수 있다.

PRB 지진격리장치의 거동특성은 Fig. 4에 나타내었다. 격 리장치는 지진 강도와 단계별 변위에 따라 거동하며 단계별 변 위는 설계변위, 초과지진, 극한지진, 초극한 지진의 4 단계로 구분된다. 상시 및 지진 시 발생하는 설계변위에 대해서는 기 
존 상용화된 탄성받침과 동일하게 격리장치의 탄성체가 거동 하여 변위를 수용한다. 이후, 그 이상의 변위가 발생하면 탄성 받침은 격리장치로서의 기능을 발휘하지 못하지만, PRB 지진 격리장치는 모듈화된 장치들이 작동하여 추가적인 변위를 수 용할 수 있게 된다.

각 모듈화된 장치들의 원리는 다음과 같다. 먼저 초과지진 에 대해서는 하판에 부착된 쐐기와 상판에 결합된 초기전단저 항 블럭(Fig. 3(b))이 부딪치면서 격리장치의 거동을 제한한다. 그 이후 극한지진에 대해서는 초기전단저항 블럭과 낙교방지 블럭(Fig. 3(d))의 연결된 지점이 파괴되고 함께 연결되어 있는 완충장치인 MER-Spring(Fig. 3(c))이 작동되어 추가적인 변위 를 수용한다. 마지막으로 초극한 지진에 대해서는 초기전단저 항 블럭과 완충장치가 쐐기로 인해 낙교방지블럭 내부로 밀려 들어가게 되고 쐐기와 낙교방지 블럭이 맞물려 더 이상의 변위 를 수용하지 않으며 낙교를 방지함으로써 교량 피해를 최대한 억제할 수 있다. 위와 같은 방법으로 추가적인 변위를 수용함 으로써 PRB 지진격리장치는 탄성받침에서 용량에 제한이 있 는 문제점을 해결할 수 있다.

Fig. 5는 PRB 지진격리장치와 상용화된 탄성받침의 거동특 성을 비교한 곡선이다. 그림에서 $\mathrm{A}$ 는 $\mathrm{PRB}$ 지진격리장치가 일 반적인 탄성받침에 비해 추가적으로 변위를 수용할 수 있음을

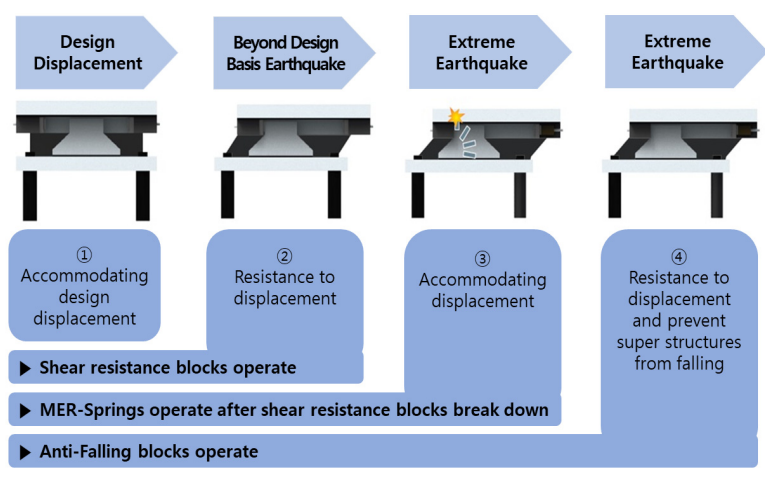

Fig. 4 Behavior characteristics of PRB isolation device

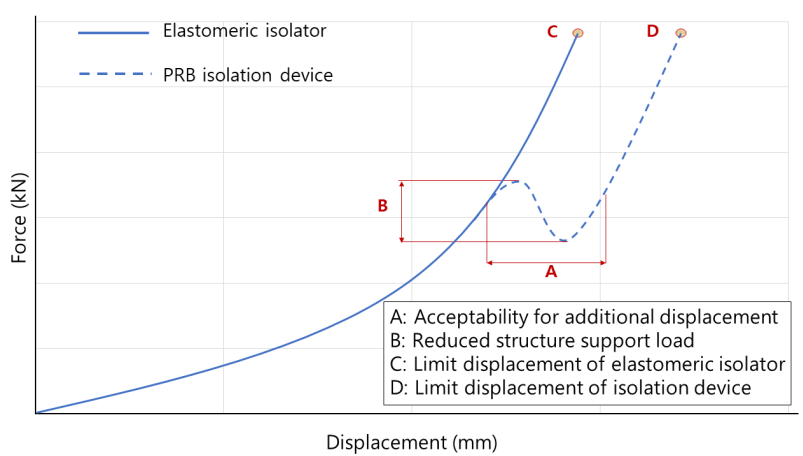

Fig. 5 Force-displacement curves of elastomeric isolator and PRB isolation device
의미한다. PRB 지진격리장치에서 초기전단저항 블럭이 파괴 된 이후, 낙교방지블럭 내부로 밀려 들어가도록 설계되어 있 으므로, 추가적으로 수용할 수 있는 변위는 초기전단저항 블 럭의 길이만큼 수용할 수 있다. $\mathrm{B}$ 는 완충장치로 인하여 받침에 작용하는 하중이 감소함을 나타낸다. C, $\mathrm{D}$ 는 각 각의 격리장치 가 수용할 수 있는 상부구조의 최대 거동 범위를 나타내며 PRB 지진격리장치와 탄성받침이 수용 가능한 최대하중이 같을 때, $\mathrm{PRB}$ 지진격리장치는 탄성받침보다 더 많은 상부구조의 변위 를 수용할 수 있다는 것을 확인할 수 있다. 이와 같은 거동특성 을 유한요소해석 프로그램을 이용하여 확인하였으며, 그 내용 을 3절에서 설명하고자 한다.

\section{PRB 지진격리장치의 유한요소해석}

\section{1 모델링}

본 연구에서 유한요소해석은 ABAQUS(ABAQUS, 2016)를 이용하여 수행되었으며, 유한요소모델은 Fig. 6 과 같다. PRB 지진격리장치의 거동에서 핵심사항은 초기전단저항 블럭이 초과지진의 변위를 수용하고 블럭의 파괴 후 완충장치에 의해 추가적인 변위를 수용할 수 있는 특성이므로, 모듈화된 장치 들 중 이 거동과 직접적으로 관련이 있는 초기전단저항 블럭과 완충장치를 유한요소해석을 위한 모델로 구현하였다. 유한요 소해석 모델은 3차원 8-node 요소를 이용하였고, 요소 수는 19,045 개, 절점 수는 22,168 개로 제작되었다. 2절에서 언급된 것처럼 초기전단저항 블럭은 SM355, 완충장치는 폴리우레탄 의 물성치를 적용하였다. ABAQUS에서 각 장치에 적용된 물 성은 SM355인 경우, 강재기호 및 재료강도(KS16, KS18)를 참
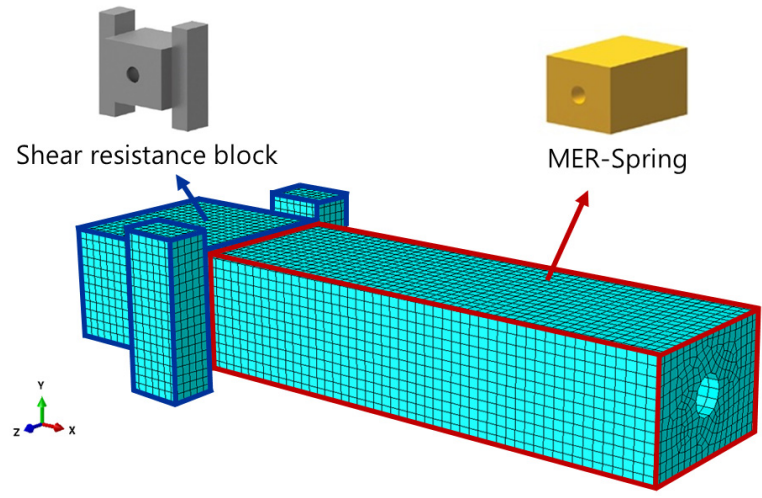

Fig. 6 Simulation model for shear resistance block and MER-Spring

Table 1 Materials used for each device

\begin{tabular}{|c|c|c|}
\hline & Shear resistance block & MER-Spring \\
\hline \multirow{2}{*}{$\begin{array}{c}\text { Materials } \\
\text { models }\end{array}$} & Plastic & \multirow{2}{*}{ Hyperelastic } \\
\cline { 2 - 2 } & Ductile damage & \\
\hline
\end{tabular}


고하였고, 폴리우레탄은 실험을 통해 얻은 결과를 활용하여 응력-변형률 곡선으로 적용되었으며, 각 장치의 요소에 사용 된 재료모델은 Table 1과 같다.

극한지진에 의한 초기전단저항 블럭의 파괴를 나타내기 위 해 연성 손상(Ductile damage) 모델을 적용했다(Khelifa et al., 2007; Ruzicka et al., 2013). 연성 손상은 사용자가 지정한 재료 특성에 따라 변위 혹은 파괴 에너지(Fracture energy)를 기준으 로 일정 수치를 초과하면 요소가 파괴되고( $\mathrm{Hu}$ and Wittmann, 1992), 해석 결과에서 파괴 여부를 확인할 수 있다. 본 연구에서 는 초기전단저항 블럭의 파괴를 묘사하기 위해 파괴 기준으로 파괴 에너지를 사용하였으며, 파괴에너지, $G_{f}$ 는 식 (1)과 같이 표현된다.

$$
G_{f}=\int_{\bar{\varepsilon}_{0}}^{\overline{\varepsilon_{f}}} \bar{\varepsilon}_{f} L \sigma_{y} d \bar{\varepsilon}^{p l}=\int_{0}^{\bar{u}_{f}^{p l}} \sigma_{y} d \bar{u}^{p l}
$$

여기서, $(\overline{-})$ 는 등가 물리량을 나타내며, $\sigma_{y}$ 는 소성변형 중 재 료의 항복응력, $\bar{\varepsilon}_{0} p l$ 과 $\bar{\varepsilon}_{f}^{p l}$ 은 항복과 파괴 시 소성 변형률을 의미 한다. $\bar{u}_{f}^{p l}$ 은 파괴 시 소성 변위를 나타내며, $L$ 은 특성길이로, 본 모델에서는 유한요소 모델의 요소길이가 사용되었다. 그리 고 파괴시 변형률, 응력 3축비(Stress triaxiality), 변형률의 변 화량(Strain rate)은 초기전단저항 블록만을 추가로 해석하여 적용하였다. 초기전단저항 블럭의 파괴해석을 수행하기 위해 서 동해석(Dynamic analysis)과 양해법(Explicit method)을 이 용하여 해석을 수행하였다(Prior, 1994; Sun et al., 2000). 완충 장치에서는 폴리우레탄의 비선형 거동특성(Sarva et al., 2007) 을 묘사하기 위해 포아송비가 0.49 인 초탄성(Hyperelastic) 모 델이 적용되었고(Gajewskia et al., 2015; Shahzad et al., 2015), 응력-변형률 곡선과 해석의 용이성을 위해 오든(Odgen)모델 로 초탄성을 나타내었다. 유한요소모델의 경계조건은 실제

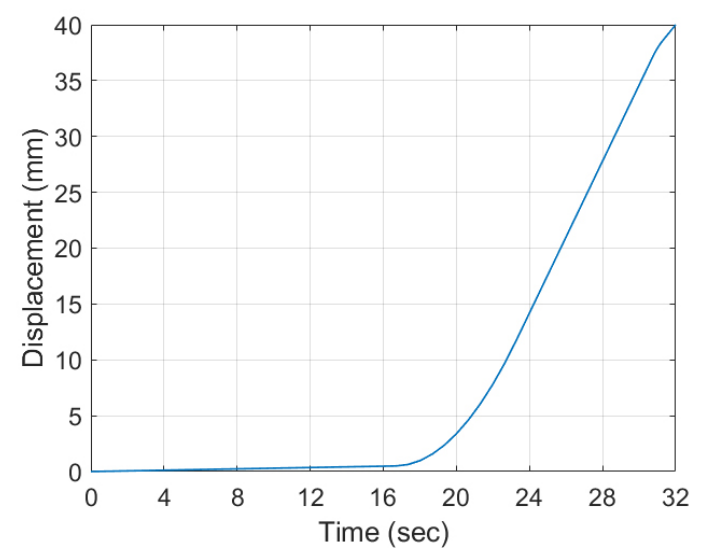

Fig. 7 Time-history curve of applied displacement
$\mathrm{PRB}$ 지진격리장치에서 변위수용가이드, 낙교방지블럭 등으 로 인한 조건을 동일하게 구현하였다. 완충장치의 최대 변위 인 $40 \mathrm{~mm}$ 를 초기전단저항 블럭 앞부분에 변위 조건으로 적용 하여 해석을 수행하였으며, Fig. 7에 시간에 따른 변위 조건을 나타내었다. 초기전단저항 블럭의 파괴는 총 $40 \mathrm{~mm}$ 의 변위 조 건에 비해 상대적으로 짧은 구간에서 발생하기 때문에 시간당 변위 기울기가 크게 적용하게 되면, 해석 결과에서 파괴를 나 타내지 못하거나 해석이 수행되지 않는 문제점이 발생한다. 그러므로 초기에는 시간당 변위의 기울기를 작게 설정하고, 초기전단저항 블럭에서 파괴가 일어난 이후에 기울기를 증가 시켜 해석을 수행하였다. 반복적인 해석을 수행해 본 결과 파 괴가 일어난 이후 그래프의 기울기가 변하여도 결과값엔 큰 차 이가 없는 것을 확인하였고, 해석 결과와 실험 결과의 비교분 석이 용이하도록 해석시간을 적용하였다.

\section{2 유한요소해석 결과 및 분석}

해석모델을 사용하여 해석을 수행하고, Fig. 8에 시간에 따 른 지진격리장치에 작용하는 하중변화로 나타내었다. 하중은 시간에 따라 증가하는 추세를 보이다가 초기전단저항 블럭의 파괴 직전에 최댓값에 도달하며, 약 $271.86 \mathrm{kN}$ 에서 초기전단저 항 블럭이 파괴되는 것으로 나타났다. 최대하중 이후 0 으로 급 격히 감소하는 것은 재료모델을 적용할 때 초기전단저항 블럭 의 파괴를 나타내기 위해서 연성 손상을 적용하였기 때문이다. 연성 손상을 적용할 때, 파괴 기준을 파괴 에너지로 선정하였 으므로 모델 내부에 하중으로 의해 축적되는 에너지가 파괴 에 너지를 초과하면 파괴가 발생하고,하중이 0 으로 급격히 감소 한다. 하중이 0 으로 감소하였다가 시간이 지남에 따라 다시 증 가하는 것은 초기전단저항 블럭이 파괴된 후 완충장치가 하중 과 변위를 수용하면서 나타나는 거동이다.

Fig. 9 에 실험을 통해 얻은 결과에서 초기전단저항 블럭과

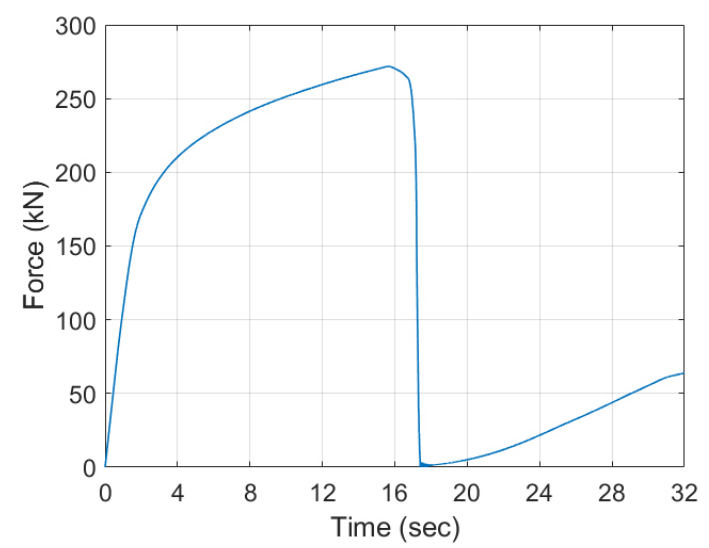

Fig. 8 Force-time curve of analysis result 


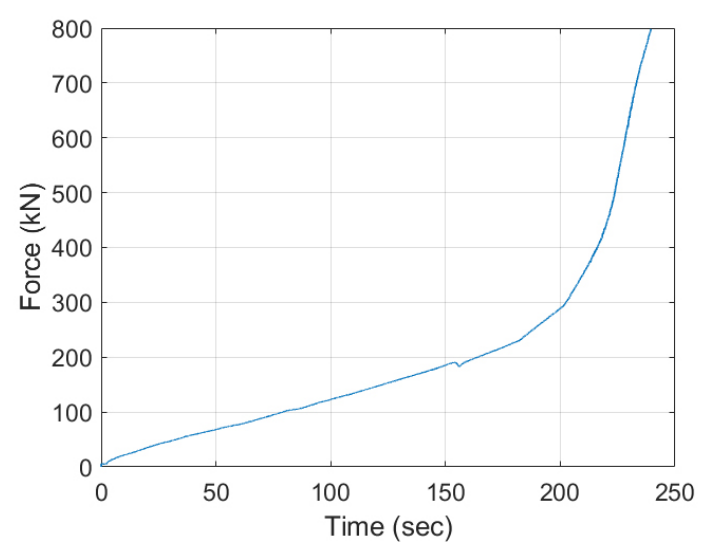

Fig. 9 Expected behavior of elastomeric pad and anti-falling block

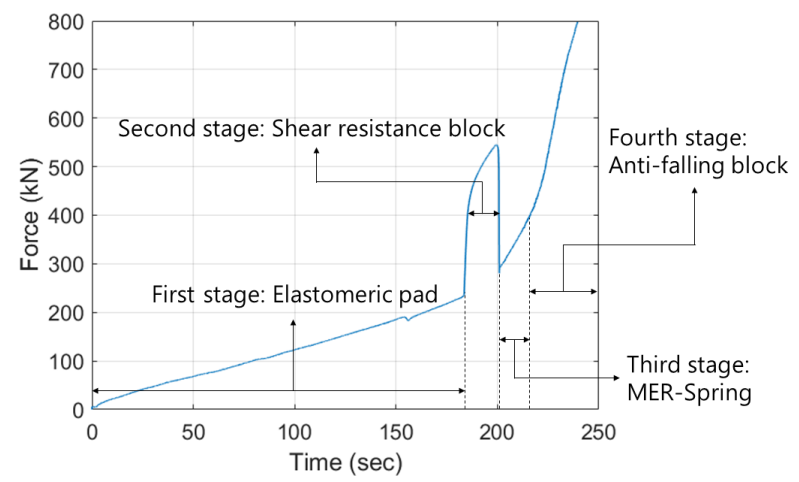

Fig. 10 Force-time curve including elastomeric pad and anti-falling block to the analysis result
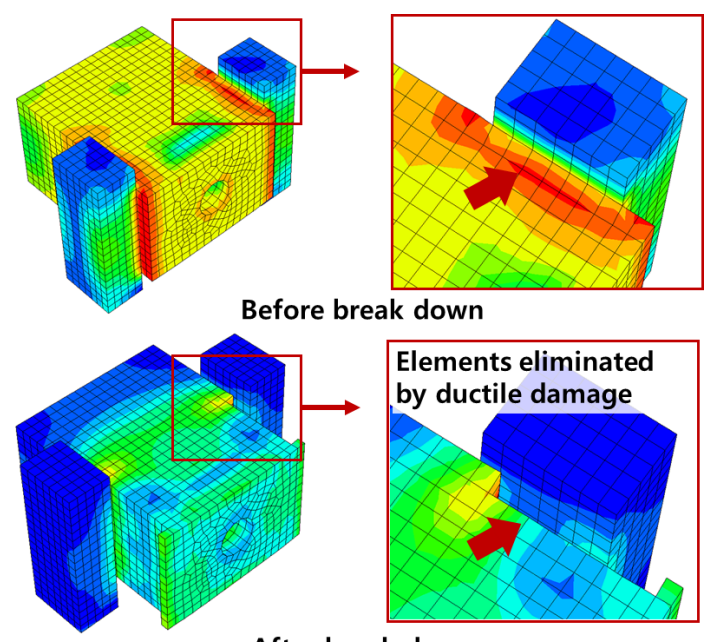

After break down

Fig. 11 Shape of shear resistance block before break down and after break down

완충장치의 거동을 제외하고 탄성체와 낙교방지블럭의 거동 특성을 곡선으로 나타내었다. 이를 Fig. 8에 나타낸 해석 결과 와 중첩하면 Fig. 10과 같은 PRB 지진격리장치 시스템의 거동 을 표현하는 곡선을 얻을 수 있으며, Fig. 5 에서 설명한 것과 같 이 모듈화된 장치들이 변위에 따라 단계별로 거동하는 것을

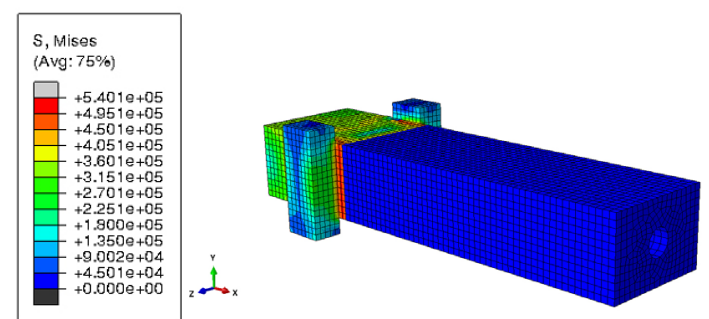

(a) Before break down of shear resistance block

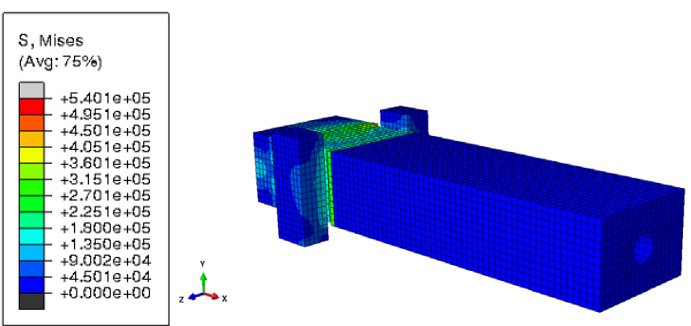

(b) After break down of shear resistance block
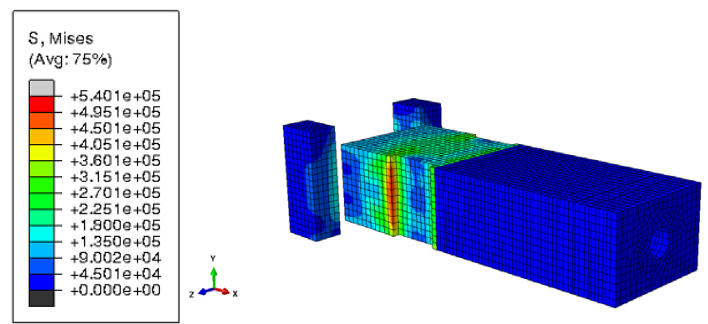

(c) At maximum displacement of the model

Fig. 12 Simulation results of deformed configuration with von-mises stress distribution

확인할 수 있다.

Fig. 10 에 나타낸 것과 같이 약 180 초까지 탄성체가 거동하 고, 약 180 초에서 약 200 초까지는 초기전단저항 블럭의 거동 이 확인된다. 초기전단저항 블럭이 파괴된 후 완충장치가 약 200 초에서 210 초 정도까지 작동하며 그 이후엔 낙교 방지블럭 이 힘을 저항함으로써 하중이 급격히 증가하는 것을 확인할 수 있다. 그리고 초기전단저항 블럭에서 파괴가 일어날 때, 연성 손상에 의해 파괴되는 요소가 제거되는 유한요소해석 결과를 Fig. 11에 제시하였으며, 유한요소모델의 응력분포는 von-Mises 응력을 통해 확인하였다.

Von-Mises 응력분포는 초기전단저항 블럭의 파괴 직전, 파 괴 직후, 파괴 후 완충장치 거동 시점으로 나누어 Fig. 12에 각 각 제시하였다.

해석을 통해 PRB 지진격리장치의 거동특성을 확인한 결과, 모듈화된 장치들이 적용된 받침이 기존의 탄성받침보다 추가 적으로 변위를 수용할 수 있는 것으로 확인되었다. 위와 같은 해석 결과를 검증하기 위해 해석에 사용한 치수, 형상, 재료물 성 등을 동일하게 하여 제작한 PRB 지진격리장치를 사용하여 실제 실험을 통해 성능평가를 수행하였다. 


\section{PRB 지진격리장치 성능평가}

\section{1 실험조건 및 방법}

실험에 사용하기 위하여 제작된 PRB 지진격리장치는 Fig. 13 과 같다. PRB 지진격리장치에의 앵커소켓은(Fig. 2) 지진격리 장치와 하부구조의 부착성을 높이기 위한 목적으로 제작되는 것 이므로, 실험에 사용한 지진격리장치는 앵커소켓을 제외하고 제작되었다. 실험에 사용된 모듈화된 장치들은 모두 SM355를 이용하여 제작되었으며, 완충장치는 폴리우레탄 재질로 제작 되었다.

실험은 Fig. 14 와 같은 면진장치 성능시험기를 활용하였으 며, 시험기의 제원은 Table 2에 나타내었다. 시험기의 상부가 지진격리장치의 상판과 체결되고, 시험기의 하부가 지진격리 장치의 하판과 체결된다. 시험기 하부가 거동하여 지진격리장 치에 하중이 전달되며 본 실험에서는 수직하중을 $1000 \mathrm{kN}$ 으로 적용하고, 약 $0.5 \mathrm{~mm} / \mathrm{sec}$ 의 속도로 거동하여 $\mathrm{PRB}$ 지진격리장 치에 작용하는 수평하중을 측정하였다.

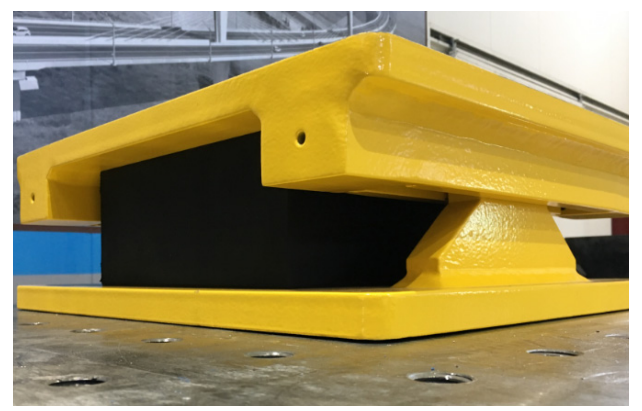

Fig. 13 PRB isolation device used in the experiment

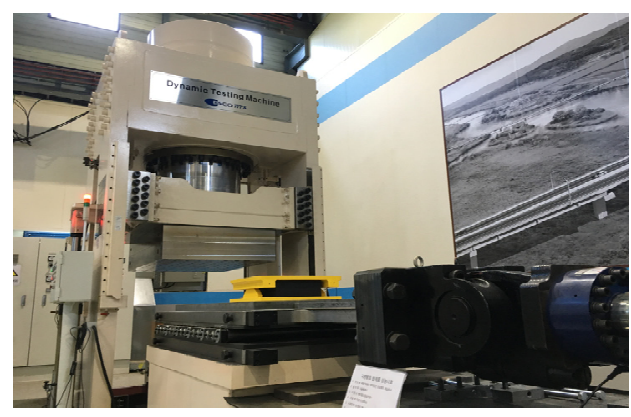

Fig. 14 Dynamic testing

Table 2 Specification of dynamic testing machine

\begin{tabular}{|c|c|c|c|}
\hline & $\begin{array}{c}\text { Max. force } \\
(\mathrm{kN})\end{array}$ & $\begin{array}{c}\text { Max. stroke } \\
(\mathrm{mm})\end{array}$ & $\begin{array}{c}\text { Max. velocity } \\
(\mathrm{mm} / \mathrm{sec})\end{array}$ \\
\hline $\begin{array}{c}\text { Vertical } \\
\text { actuator }\end{array}$ & 15,000 & 750 & 8 \\
\hline $\begin{array}{c}\text { Horizontal } \\
\text { actuator }\end{array}$ & 1,000 & 500 & 100 \\
\hline
\end{tabular}

실험방법은 KS F 4420(2018) 기준을 따라서 수행되었고 실 험결과는 시간에 따른 PRB 지진격리장치에 작용되는 하중으 로 나타내었으며, 해석 결과와 비교 및 분석을 통해 지진격리 장치의 성능을 평가하였다.

\section{2 실험결과 및 분석}

4.1절에서 설명한 PRB 지진격리장치의 실험결과는 Fig. 15 에 나타내었다.

약 180 초까지 PRB 지진격리장치의 탄성체가 거동하고 약 180 초에서 약 205 초까지는 초기전단저항 블럭이 거동하며 초 기전단저항 블럭이 파괴된 이후인 205 초에서 약 215 초까지는 완충장치가 거동하였다가 낙교방지블럭으로 인해 하중이 급 격히 증가하였다. 실험결과, 초기전단저항 블럭의 하중-시간 곡선과 해석 결과 간 차이가 발생함을 확인하였다. 해석에서 는 초기전단저항 블럭이 파괴가 시작된 후 하중이 급격히 감소 하지만, 실제 실험에서는 속도를 약 $0.5 \mathrm{~mm} / \mathrm{sec}$ 로 고정하여 진 행하였으므로 시간이 지남에 따라 하중이 감소하는 경향이 나 타난다. 실험 및 해석 결과에서 초기전단저항 블럭이 파괴되는 시점의 하중은 실험에서는 $519.37 \mathrm{kN}$ 으로 나타났으며, 해석에 서는 $545.31 \mathrm{kN}$ 으로 약 $4.76 \%$ 의 오차가 발생하였다. 유한요소 해석을 통한 동해석과 실제 실험의 결과를 비교했음을 고려했 을 때, $4.76 \%$ 의 오차는 해석의 결과가 신뢰할 수 있는 수준임 을 확인하였다.그리고 낙교방지블럭이 거동하는 단계에서 최 대하중은 약 $798.266 \mathrm{kN}$ 으로 확인할 수 있다. 구텐베르크-리히 터 법칙(Gutenberg-Richter Law, GR 법칙)을 이용하여 대규모 지진을 최대지반가속도 $0.55 \mathrm{~g}$ 로 환산하여 약산식에 의거한 개 략적인 계산을 해보면 대규모 지진이 발생할 때, PRB 지진격 리장치의 허용질량은 147.95 ton인 것을 알 수 있다. 이에 반해 받침규격에서 $\mathrm{PRB}$ 지진격리장치의 탄성체와 동일한 규격인 $400 \mathrm{~mm} \times 250 \mathrm{~mm}$ 인 경우, 받침의 허용질량은 101.937 ton으로

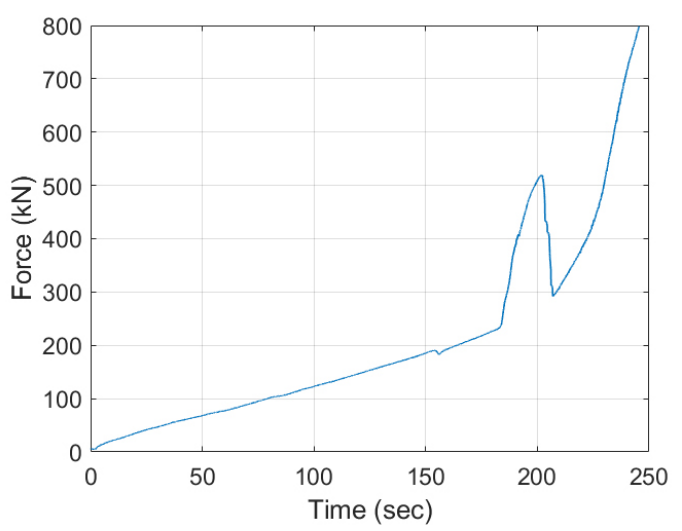

Fig. 15 Force-time curve of experiment result 


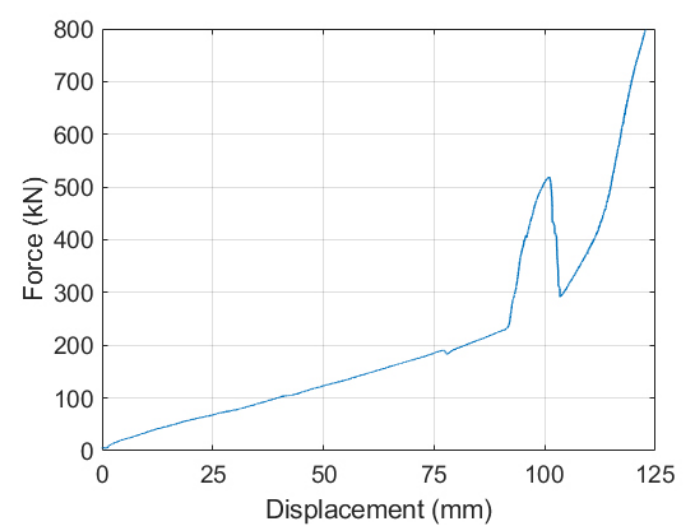

Fig. 16 Force-displacement curve of PRB isolation device

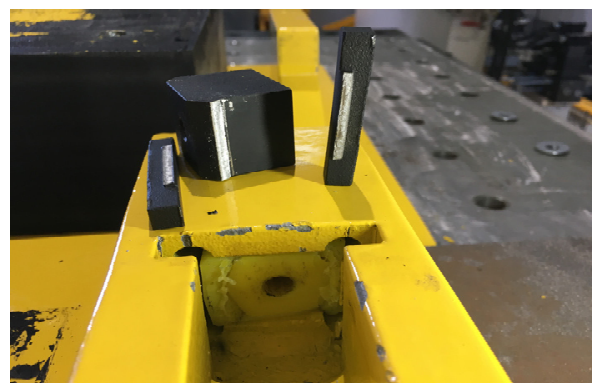

Fig. 17 Shape of shear resistance block after break down

$\mathrm{PRB}$ 지진격리장치의 허용질량이 더 높은 것을 알 수 있다. 그 러므로 PRB 지진격리장치는 대규모 지진으로 인한 구조물의 손상 방지가 가능한 것으로 예상된다. PRB 지진격리장치 거 동특성의 일반성을 높이기 위하여 하중-변위곡선을 Fig. 16에 나타내었고 해석과 실험을 통해 PRB 지진격리장치가 설계에 서 고안된 것과 마찬가지로 변위에 따라 단계별로 거동하는 것 을 확인하였다. 실험을 통해 초기전단저항 블럭이 파괴된 형 상은 Fig. 17에 나타내었다.

\section{5. 결 론}

본 연구에서는 기존 탄성받침에서 이탈, 찢어짐, 롤오버, 낙 교 등 문제점을 개선하기 위해 변형성능에 기초한 지진격리장 치인 PRB 지진격리장치를 개발하였다. 개발된 지진격리장치 는 상시 및 지진 시, 초과지진, 극한지진, 초 극한지진으로 4단 계에 따른 거동을 모듈화된 장치들이 수용할 수 있도록 설계되 었다. 이에 따라 지진격리장치의 유한요소해석을 통해 PRB 지진격리장치의 거동을 확인하였고, 실제 실험을 통해서 그 성능을 평가하였다.

1) 지진의 규모가 커질수록 탄성받침에 전달되는 변위 및 하중도 증가하게 되므로 이를 소산하기 위해선 탄성받 침의 크기가 커져야 하지만 구조물의 공간적인 한계에
의해 탄성받침의 크기에는 한계가 있다. 이러한 제한사 항을 모듈화된 장치인 초기전단저항 블럭과 변위수용가 이드, 완충장치, 낙교방지블럭 등을 탄성받침에 적용하 여 추가적인 변위를 수용하도록 함으로써 개선하였다. 개발된 지진격리장치의 이론적인 거동특성이 구현되는 지 확인하기 위해 유한요소해석 프로그램인 ABAQUS 를 통해 핵심장치인 초기전단저항 블럭과 완충장치를 모델링하여 해석을 수행하였다. 그 결과 변위에 따라 초 기전단저항 블럭이 파괴되고, 파괴 이 후 완충장치의 거 동을 확인하였으며, 탄성체와 낙교방지블럭의 거동을 포함한 PRB 지진격리장치의 거동을 확인하여 변위에 따른 지진격리장치의 단계별 거동이 구현됨을 확인하 였다.

2) $\mathrm{PRB}$ 지진격리장치의 성능을 평가하기 위해 장치를 실 제로 제작하였고, 면진장치 성능시험기를 활용하여 실 험을 진행하였다. 실험 결과와 해석 결과를 비교한 결과, 초기전단저항 블럭이 파괴된 직후 하중이 감소하는 구 간에서 거동에 차이가 발생함을 확인했다. 실제 시험에 서는 지진격리장치가 파괴 이후 서서히 하중이 감소하 나, 해석에서는 모델링 기법의 영향으로 전단블럭이 파 괴되며 하중이 비교적 급격히 감소하였다. 또한, 실험 및 해석 결과에서 초기전단저항 블럭이 수용할 수 있는 최 대하중의 오차가 약 $4.76 \%$ 발생하였지만, 해석의 결과 가 신뢰할 수 있는 수준으로 판단되었다. 해석과 실험을 통해 PRB 지진격리장치가 설계된 의도에 따라 단계별 로 거동하는 것으로 확인하였으며, 향후 사용된 재료의 물성에 대한 추가적인 분석과 지진격리장치의 성능향상 을 위한 보완 방향에 관한 연구를 수행할 예정이다. 또, 지진격리장치는 실제 지진 시에 충격으로 인해 파괴가 발생할 수 있으므로 여러 가지 하중을 이용하여 실험과 해석을 통해 지진격리장치의 성능평가에 관한 연구를 진행할 예정이다.

\section{감사의 글}

본 연구는 중소기업기술정보진흥원이 주관하는 창업성장 기술개발사업(No. S2693145, S2796792)의 지원을 받아 수행 되었습니다.

\section{References}

ABAQUS, Version 6.14 (2016) Online Documentation Help, Theory Manual: Dassault Systemes. 
Gajewskia, M., Szczerbab, R., Jemiołoa, S. (2015) Modelling of Elastomeric Bearings with Application of Yeoh Hyperelastic Material Model, Procedia Eng., 111, pp.220 227.

Hu, X.-Z., Wittmann, F.H. (1992) Fracture Energy and Fracture Process Zone, Mater. \& Struct., 25, pp.319 326.

Keum, D.H., Noh, P.S., Kim, J.U. (1994) A Study on the Improvement of Earthquake Resistant Design Code, Archit. Inst. Korea, pp.435 440.

Khelifa, M., Oudjene, M., Khennanec, A. (2007) Fracture in Sheet Metal Forming: Effect of Ductile Damage Evolution, Comput. \& Struct., 85(3- 4), pp.205 212.

Kim, J.S., Jung, J.P., Moon, J.H., Lee, T.H., Kim, J.H., Han, T.S. (2019) Seismic Fragility Analysis of Base-Isolated LNG Storage Tank for Selecting Optimum Friction Material of Friction Pendulum System, Earthq. \& Tsunami, 13(2), p.28.

KS F 4420 (2018) Steel-Laminated Elastomeric Bearings for Bridge.

Lee, K.K., Kim, H.D., Choi, S.M. (2017) Major Revision of Material Part of Design Standards for Structural Steel Buildings According to change of KS, Maga. \& J. Korean Soc. Steel Constr., 29(5), pp.7 11.
Priestley, M.J.N. (2000) Performance based Seismic Design, New Zealand Soc. Earthq. Eng., 33(3), pp.325 346.

Prior, A.M. (1994) Applications of Implicit and Explicit Finite Element Techniques to Metal Forming, Mater. Proc. Technol., 45(1-4), pp.649 656.

Ruzicka, J., Spaniel, M., Prantl, A., Dzugan, J., Kuzelka, J., Moravec, M. (2013) Identification of Ductile Damage Parameters in the Abaqus, Bull. Appl. Mech., 9, p.89.

Sarva, S.S., Deschanel, S., Boyce, M.C., Chen, W. (2007) StressStrain Behavior of a Polyurea and a Polyurethane from Low to High Strain Rates, Polymer, 48(8), pp.2208 2213.

Shahzad, M., Kamran, A., Siddiqui, M.Z., Farhan, M. (2015) Mechanical Characterization and FE Modelling of a Hyperelastic Material, Mater. Res., 18(5), pp.918 924.

Sun, J.S., Lee, K.H., Lee, H.P. (2000) Comparison of implicit and explicit finite element methods for dynamic problems, Mater. Proc. Technol., 105(1-2), pp.110 118.

요 지

본 논문에서는 모듈화(Module)된 부품을 활용한 탄성받침 성능개선기법에 대하여 소개하였다. 각각의 모듈화된 장치들이 지진 강 도 및 이동 변위에 따른 단계별 거동을 함으로써 받침의 성능을 개선하게 된다. 모듈화된 장치들은 초기전단저항 블럭, 완충장치, 변 위수용가이드, 낙교방지블럭이 있으며, 탄성받침에 추가적으로 적용되었다. 이 장치는 지진의 규모에 따라 4 단계로 거동하며, 1 차로 설계변위를 수용하고, 2 차, 3 차에서는 대규모 지진을 수용하며, 4 차로는 대규모의 지진에 대해서 낙교방지가 가능하도록 설계되어 탄 성받침의 용량 제한을 증가시킨다. 본 논문에서는, 개발기술인 PRB 지진격리장치를 유한요소해석을 통해 해석하여 격리장치의 이론 적인 거동이 구현되는지와, 대규모 지진에 해당하는 하중을 견딜 수 있는지 확인하였다. 그리고 이를 바탕으로 실험을 통해 성능평가 를 진행하여 두 결과의 비교 분석을 통해 PRB 지진격리장치가 탄성받침의 성능을 개선할 수 있는지 검증하였다.

핵심용어 : 지진격리장치, 성능기반 고무받침, 폴리머 스프링, 유한요소해석 